\title{
Estimating the probability of stroke in Korean hypertensive patients visiting tertiary hospitals using a risk profile from the framingham study \\ Cheol Ung Choi and Chang Gyu Park*
}

Address: Cardiovascular Center, Korea University Guro Hospital, Seoul, Korea

Email: Cheol Ung Choi - wmagpie@medimail.co.kr; Chang Gyu Park* - wmagpie@korea.com

* Corresponding author

Published: 22 April 2009

BMC Neurology 2009, 9:16 doi:10.1186/1471-2377-9-16

This article is available from: http://www.biomedcentral.com/I47/-2377/9//6

(C) 2009 Choi and Park; licensee BioMed Central Ltd.

This is an Open Access article distributed under the terms of the Creative Commons Attribution License (http://creativecommons.org/licenses/by/2.0), which permits unrestricted use, distribution, and reproduction in any medium, provided the original work is properly cited.
Received: 26 October 2008
Accepted: 22 April 2009

\begin{abstract}
Background: Hypertension is the most important single modifiable risk factor for stroke. We investigated the distribution of stroke risk factors and 10 -year probability of stroke in Korean hypertensive patients.

Methods: A total of I,402 hypertensive patients treated by cardiology departments at 37 general hospitals nationwide were enrolled. Risk factors for stroke were evaluated using a series of laboratory tests and physical examinations, and the 10-year probability of stroke was determined by applying the Framingham stroke risk equation.

Results: The proportion of patients who have uncontrolled hypertension despite use of antihypertensives was $37.2 \%(37.2 \%$ women, $37.3 \%$ men, $p=0.990)$. The average 10-year probability of stroke in hypertensive patients was $24.27 \%$ ( $24.17 \%$ women, $24.39 \%$ men, $p=0.825$ ), approximately 2.4 times higher than of the risk of stroke observed in the Korean Cancer Prevention Study [KCPS] cohort. The 10-year stroke probability in patients with hypertension increased in proportion to age. In patients for hypertension, the 10-year probability of stroke increased in proportion to blood pressure.
\end{abstract}

Conclusion: Aggressive interventions are mandated to reduce blood pressure and alleviate the high risk of stroke in hypertensive patients.

\section{Background}

Hypertension (HTN) is one of the most common chronic diseases in adults. Major complications of HTN include ischemic heart disease, stroke, heart failure, renal failure, aortic and peripheral arterial diseases. Stroke is a leading cause of death and disability among individuals older than 65 years in Korea. The total number of deaths attributable to stroke in Korea is estimated at $13.9 \%$ and associated annual medical costs account for more than $10 \%$ of total medical expenditures $[1,2]$. In addition, stroke is becoming a major cause of death and behavioral disorders due to the rapidly aging Korean population [3].

Although various factors induce stroke, HTN and aging are known to be most common risk factors of stroke worldwide [4,5]. Aging is an irreversible factor, but HTN is controllable. Appropriate treatment of HTN has been shown to reduce the risk of stroke by $40 \%$ and the risk of acute myocardial infarction by 15\% [6]. According to related research, an increase of systolic blood pressure 
(SBP) and diastolic blood pressure (DBP) 20/10 $\mathrm{mmHg}$ from 115/75 $\mathrm{mmHg}$ doubles the risk of stroke [6].

The Framingham Study, a reliable prospective epidemiology study on chronic diseases established in the United States in 1948, revealed that risk factors of stroke include age, SBP, use of anti-hypertensives, diabetes, smoking, cardiovascular diseases (CVD), atrial fibrillation, and left ventricular hypertrophy (LVH) [7-9]. The average 10-year probability of stroke in the total Korean Cancer Prevention Study (KCPS) cohort was 3.5\% for males and 3.7\% for females, and the average 10-year probability of stroke in the 55-84 years of age group within the KCPS cohort was $10.0 \%$ for males and $9.0 \%$ for females [10]. Wolf et al. showed that for each $10 \mathrm{mmHg}$ increase in SBP, the risk of stroke increased by $91 \%$ for men and $68 \%$ for women [7]. Although hypertension is the most important single modifiable risk factor for stroke, there is little data about the practical 10 year stroke risk in hypertensive patients. We reported previously that the 10-year risk of stroke in Korean hypertensive patients visiting community-based hospitals was approximately 4.6 times higher than of the risk of stroke in of the KCPS cohort [11]. However, the enrolled patients were limited to only patients visiting community-based hospitals. Therefore, we planned to evaluate the 10-year probability of stroke in Korean hypertensive patients visiting tertiary hospitals using the Framingham risk score [7].

\section{Methods}

\section{Study population}

We conducted a multicenter study evaluating patients treated by the cardiology departments of 37 general hospitals in Korea. Our study population included 1735 patients with HTN between 55 and 84 years of age. We excluded 333 subjects due to a previous history of stroke. Consequently, 1402 patients ( 769 male, 633 female) were enrolled in the study. All subjects gave written informed consent. This study was approved by the local ethics committee.

\section{Laboratory and lifestyle factors measurement}

Body weight and height were measured with subjects wearing light clothing and without shoes. The body mass index (BMI) was calculated as the weight in kilograms divided by the height in meters squared. The waist circumference was measured from the narrowest point between the lower borders of the rib cage and the iliac crest.

Blood pressure was measured in the right arm, using an appropriately sized cuff and a standard mercury sphygmomanometer, after the subjects had been seated for at least $15 \mathrm{~min}$, with feet on the floor and arm supported at heart level.
Fasting blood samples were obtained in the morning after at least 8 hours of fasting. Plasma glucose, total cholesterol, triglyceride, high density lipoprotein (HDL)-cholesterol, and low density lipoprotein (LDL)-cholesterol were measured.

Risk factors for stroke were age, diabetes, smoking, medical history of cardiovascular disease, atrial fibrillation, LVH, hyperlipidemia, alcohol intake, physical exercise, obesity, and family history of stroke.

Antihypertensive medications that subjects were currently receiving were classified as angiotensin converting enzyme inhibitor (ACEI), angiotensin receptor blocker (ARB), calcium channel blocker (CCB), beta-blocker (BB), diuretics, and others.

\section{Estimation of 10-year probability of stroke}

The 10-year probability of stroke was estimated for each patient using the Framingham risk score [7]. The variables used to calculate the Framingham risk score are age, systolic blood pressure, anti-hypertensive therapy, diabetes mellitus, smoking, CVD, atrial fibrillation, and LVH.

\section{Study definitions}

We identified HTN with repeated measurements of $\geq 140$ $\mathrm{mmHg}$ SBP or $\geq 90 \mathrm{mmHg}$ DBP or previous diagnosis. HTN stage was classified according to Joint National Committee 7 (JNC-7) criteria [12]: normal (SBP $<120$ $\mathrm{mm} \mathrm{Hg}$ and DBP $<80 \mathrm{~mm} \mathrm{Hg})$; pre-HTN $(120 \leq \mathrm{SBP}<$ $140 \mathrm{~mm} \mathrm{Hg}$ or $80 \leq \mathrm{DBP}<90 \mathrm{~mm} \mathrm{Hg}$ ); stage $1(140 \leq \mathrm{SBP}$ $<160 \mathrm{~mm} \mathrm{Hg}$ or $90 \leq \mathrm{DBP}<100 \mathrm{~mm} \mathrm{Hg}$ ); and stage 2 (SBP $\geq 160$ or DBP $\geq 100 \mathrm{~mm} \mathrm{Hg}$ ). Uncontrolled HTN was defined as repeated measurements of $\geq 140 \mathrm{mmHg}$ SBP and $\geq 90 \mathrm{mmHg}$ DBP, despite use of antihypertensives. Diabetes was defined as fasting blood glucose concentration $\geq 126 \mathrm{mg} / \mathrm{dL}$ or taking diabetes medications. Subjects were classified as "non-smokers" (patients who never smoked before and did not smoke currently) or "smokers" (patients who had smoked within the past year or who smoke currently). Atrial fibrillation was confirmed by electrocardiogram. The product of QRS duration times the Cornell voltage combination $\left(\mathrm{R}_{\mathrm{aVL}}+\mathrm{S}_{\mathrm{V} 3}\right.$, with $6 \mathrm{~mm}$ added in women $[13,14])$ greater than $2440 \mathrm{~mm} / \mathrm{msec}$ or Sokolow-Lyon voltage $\left(\mathrm{S}_{\mathrm{V} 1}+\mathrm{RV}_{5 / 6}\right)$ greater than $38 \mathrm{~mm}$ [15] was used to identify LVH.

CVD was defined as a combination of coronary artery disease (CAD) and congestive heart failure (CHF). CAD was defined as any hospitalization for acute myocardial infarction or angina and CHF was defined as any hospitalization for CHF. If a stroke had occured within a first line relative, subjects were considered to have a family history of stroke. Dyslipidemia was defined in terms of the fol- 
lowing criteria: total cholesterol $>200 \mathrm{mg} / \mathrm{dL}$, triglyceride $>150 \mathrm{mg} / \mathrm{dL}$, HDL-cholesterol $<40 \mathrm{mg} / \mathrm{dL}$, or LDL-cholesterol > $100 \mathrm{mg} / \mathrm{dL}$.

We use the definition of metabolic syndrome as proposed by National Cholesterol Education Program Adult Treatment Panel III [16]. Target organ damage variables were serum creatinine (women $>1.2 \mathrm{mg} / \mathrm{dL}$, men $>1.3 \mathrm{mg} /$ dL), LVH (electrocardiography criteria per Cornell, and/or Sokolow-Lyon criteria $[13,15])$, microalbuminuria (women $\geq 3.5 \mathrm{mg} / \mathrm{mmol}$ in women, men $\geq 2.5 \mathrm{mg} / \mathrm{mmol}$ per 2003 guidelines of the European Society of Hypertension/European Society of Cardiology) [17], and retinal lesions following Dodson's classification [18]. Renal function alteration was also calculated, using the Cockcroft and Levey formulae, and expressed as a glomerular filtrate $<60 \mathrm{ml} / \mathrm{min}$.

\section{Statistical analysis}

Statistical analysis was performed using the SPSS 10.0 software package (SPSS Inc., Chicago, IL, USA). Continuous variables were expressed as means \pm S.D. and categor- ical variables were reported as number (\%). Continuous variables were compared using Student's t-test, or one way-ANOVA with post hoc multiple comparisons performed using Duncan's (D) multiple comparison test. Categorical variables were compared using a chi-square test or Fisher's exact test. A p $<0.05$ was considered statistically significant.

\section{Results}

\section{Baseline characteristics and risk factors}

The baseline characteristics and risk factors of our subjects are summarized in Table 1. Our sample included 633 men and 769 women. The mean age of patients was $68.41 \pm$ 7.40 years. The average SBP was $132 \pm 17 \mathrm{mmHg}$ and the average DBP was $79 \pm 10 \mathrm{mmHg}$. The prevalence of subjects taken antihypertensives was $76.0 \%$ (76.9\% women, $75.0 \%$ men, $\mathrm{p}=0.429)$. The prevalence of subjects with target organ damage was $16.3 \%$ (15.2\% women, $17.5 \%$ men, $\mathrm{p}=0.241)$. The prevalence of diabetes mellitus was $16 \%(17.2 \%$ women, $14.7 \%$ men, $\mathrm{p}=0.209)$ and the prevalence of cigarette smoking was $30.6 \% \quad(3.6 \%$ women, $63.3 \%$ men, $\mathrm{p}<0.001)$. The prevalence of CVD

Table I: Characteristics of risk factors in study subjects

\begin{tabular}{|c|c|c|c|c|}
\hline & Female & Male & Total & \\
\hline Risk factors & $(n=769)$ & $(n=633)$ & $(n=1402)$ & $P$ \\
\hline Age, years & $68.96 \pm 7.36$ & $67.74 \pm 7.40$ & $68.41 \pm 7.40$ & 0.002 \\
\hline Height, & $154.50 \pm 6.20$ & $167.24 \pm 5.79$ & $160.44 \pm 8.76$ & $<0.001$ \\
\hline Weight & $60.63 \pm 8.68$ & $69.08 \pm 9.23$ & $64.56 \pm 9.88$ & $<0.001$ \\
\hline Systolic blood pressure, $\mathrm{mmHg}$ & $133 \pm 17$ & $131 \pm 16$ & $132 \pm 17$ & 0.143 \\
\hline Diastolic blood pressure, $\mathrm{mmHg}$ & $79 \pm 10$ & $79 \pm 10$ & $79 \pm 10$ & 0.303 \\
\hline Heart rate & $71 \pm 11$ & $71 \pm 11$ & $71 \pm 11$ & 0.648 \\
\hline Glucose & $115.12 \pm 34.14$ & $113.62 \pm 37.13$ & $1 \mid 4.43 \pm 377$ & 0.491 \\
\hline Total cholesterol & $201.32 \pm 42.02$ & $184.42 \pm 41.03$ & $193.56 \pm 42.39$ & $<0.001$ \\
\hline HDLc & $49.52 \pm 29.82$ & $44.66 \pm 12.43$ & $47.28 \pm 23.56$ & $<0.001$ \\
\hline Triglyceride & $159.85 \pm 127.34$ & $156.05 \pm 108.74$ & $158.08 \pm 118.99$ & 0.573 \\
\hline LDLc & $132.00 \pm 42.22$ & $115.20 \pm 42.10$ & $12434 \pm 42.96$ & $<0.001$ \\
\hline Antihypertensives, n (\%) & 591 (76.9) & $475(75.0)$ & $1066(76.0)$ & 0.429 \\
\hline Target organ damage, n (\%) & $117(15.2)$ & III (I7.5) & $228(16.3)$ & 0.241 \\
\hline Diabetes mellitus, n (\%) & $132(17.2)$ & $93(14.7)$ & $225(16)$ & 0.209 \\
\hline Diabetes mellitus medication, $\mathrm{n}(\%)$ & 152 (19.8) & $103(16.3)$ & $255(18.2)$ & 0.091 \\
\hline Cigarette smoking, n (\%) & $28(3.6)$ & $401(63.3)$ & $429(30.6)$ & $<0.001$ \\
\hline Cardiovascular disease, n (\%) & $365(47.5)$ & $329(52.0)$ & $694(49.5)$ & 0.093 \\
\hline Atrial fibrillation, n (\%) & $54(7.0)$ & $54(8.5)$ & $108(7.7)$ & 0.292 \\
\hline Left ventricular hypertrophy, n (\%) & $218(28.3)$ & $233(36.8)$ & 451 (32.2) & 0.001 \\
\hline Dyslipidemia, n (\%) & $116(16.6)$ & 47 (7.9) & $163(12.6)$ & $<0.001$ \\
\hline Body mass index $\geq 25 \mathrm{~kg} / \mathrm{m}^{2}, \mathrm{n}(\%)$ & $231(30)$ & $149(23.5)$ & $380(27.1)$ & 0.006 \\
\hline Stroke family history, n (\%) & $94(12.2)$ & $95(15.0)$ & $189(13.5)$ & 0.129 \\
\hline Antiplatelet therapy, n (\%) & 367 (47.7) & $386(61.0)$ & $753(53.7)$ & $<0.001$ \\
\hline Warfarin therapy, n (\%) & $22(2.9)$ & $17(2.7)$ & $39(2.8)$ & 0.743 \\
\hline Lipid lowering therapy, n (\%) & $238(30.9)$ & $167(26.4)$ & 405 (28.9) & 0.06 \\
\hline Uncontrolled HTN, n (\%) & $277(36)$ & $229(36.2)$ & $506(36.1)$ & 0.736 \\
\hline 10-year probability of stroke & $24.17 \pm 20.77$ & $24.39 \pm 17.03$ & $24.27 \pm 19.16$ & 0.825 \\
\hline
\end{tabular}

HDLc: High density lipoprotein-cholesterol, LDLc: Low density lipoprotein-cholesterol, cardiovascular disease: history of myocardial infarction, angina pectoris, coronary insufficiency, intermittent claudication, or congestive heart failure. Values: Mean \pm SD or number (\%). n: number. 
was $49.5 \%$ ( $47.5 \%$ women, $52.0 \%$ men, $\mathrm{p}=0.093$ ) and the prevalence of atrial fibrillation was $7.7 \% \quad(7.0 \%$ women, $8.5 \%$ men, $\mathrm{p}=0.292)$. The prevalence of $\mathrm{LVH}$ was $32.2 \%$ (28.3\% women, 36.8\% men, $\mathrm{p}<0.001)$. Measurements of total cholesterol, HDL-cholesterol and LDL-cholesterol measurements were higher in women than in men. Prevalences of smoking, LVH, drinking, and physical exercise were higher in men than in women. The proportion of patients who had uncontrolled hypertension despite use of antihypertensives was 37.2\% (37.2\% women, 37.3\% men, $\mathrm{p}=0.990$; Figure. 1 -A) The prevalence of metabolic syndrome according to the ATP-III guideline was 28\% (26.1\% women, $30.5 \%$ men, $\mathrm{p}=$ 0.071; Figure 1-B).

\section{Average I0-year probability of stroke}

The average 10-year probability of stroke was $26.27 \%$ (26.9\% women, $25.5 \%$ men) (Table 1 ). As expected, 10year probability of stroke in patients with HTN increased in proportion to age (Table 2 ). Figure 2-A illustrates differences in the average 10-year probability of stroke between men and women according to age. Men aged 60-69 years had a higher 10-year probability of stroke than women of similar age. However, in other age groups, there were no gender-related differences. Table 2 also showed the average 10 -year probability of stroke according to blood pressure in treated hypertensive patients. Differences in the average 10-year probability of stroke between men and women, according to HTN stage, are shown in Figure 2-B. In HTN stage 2, the 10-year probability of stroke was high in women compared to men. At all other HTN stages there were no differences by gender.

As illustrated in Figure 3, the average 10-year probability of stroke was higher in patients with metabolic syndrome than in patients without metabolic syndrome.

\section{Concomitant antihypertensives taken according to age (Table 3)}

Physicians prescribed antihypertensives for hypertensive patients was as follows: ARB 48.6\%, CCB 38.7\%, betablocker 31.5\%, ACEI 9.9\%, diuretics 7.8\%, combined treatment $35.9 \%$. Of these, only diuretics were prescribed more frequently with increasing age, with the rest of these medications showing no age-related presciption trends.

\section{Discussion}

This study is an initial report designed to predict the 10year probability of stroke in Korean hypertensive patients visiting tertiary hospitals using the Framingham risk score.

We found the average 10-year probability of stroke in hypertensive patients was $26.27 \%$ (26.9\% women, $25.5 \%$ men), which was approximately 2.4 times higher than values found in a previous study of the KCPS cohort [10]. This result may be explained by the fact that $34 \%$ of the
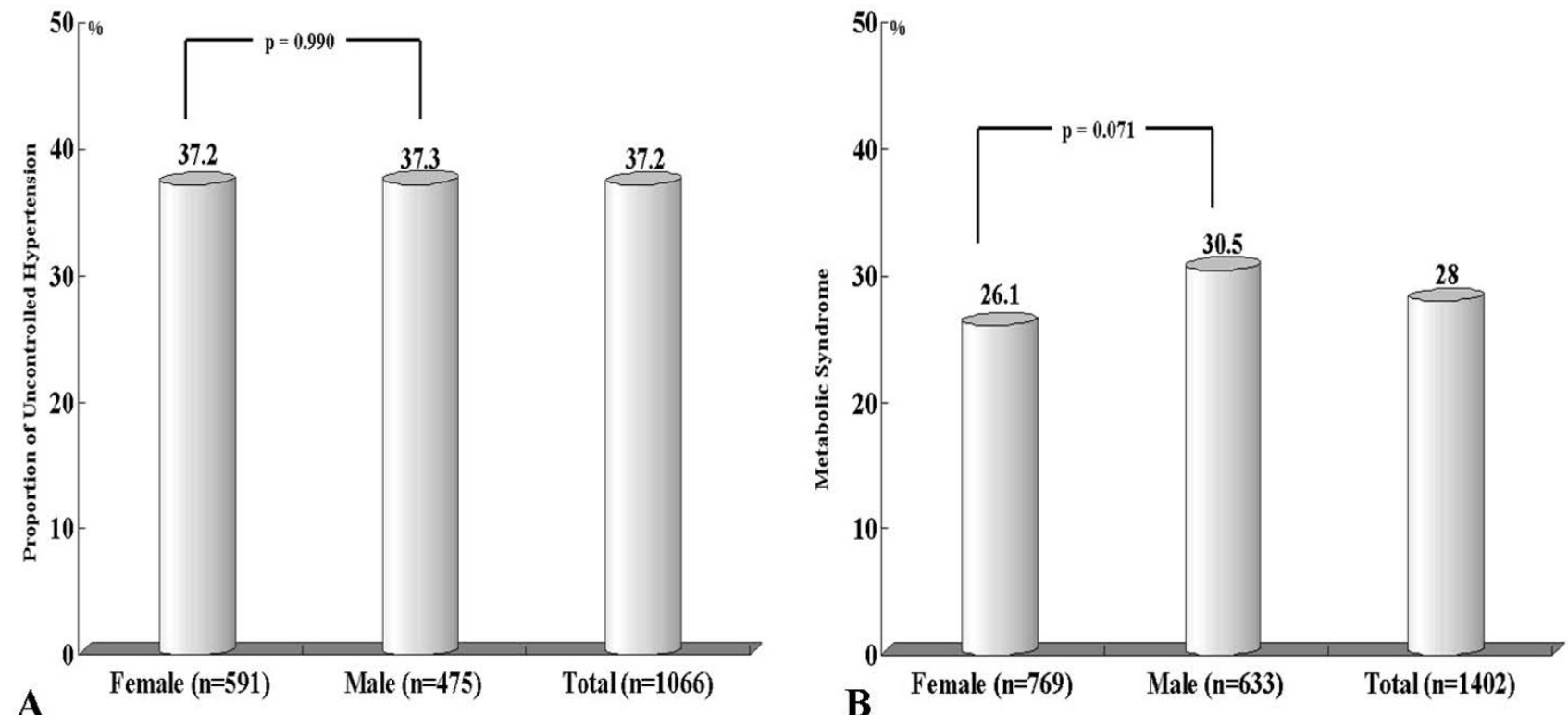

\section{Figure I}

A: Proportion of patients with uncontrolled hypertension despite use of antihypertensives. Uncontrolled $\mathrm{HTN}$ was defined as repeated measurements of $\geq 140 \mathrm{mmHg}$ SBP and $\geq 90 \mathrm{mmHg}$ DBP, despite use of antihypertensives. B: Prevalence of metabolic syndrome in patients with hypertension. 
Table 2: Average 10-year probability of stroke according to age in all subjects and blood pressure in treated hypertensive patients.

\begin{tabular}{|c|c|c|c|}
\hline Age group & 10 year risk of Stroke* & Stage of HTN & 10 year risk of Stroke* \\
\hline$<60(n=167)$ & $12.42 \pm 9.1 \mathrm{I}^{\mathrm{a}}$ & Normal (n = 134) & $21.16 \pm 17.23^{a}$ \\
\hline $60-69(n=654)$ & $18.63 \pm 13.89 b$ & Prehypertension $(n=535)$ & $26.57 \pm 18.92^{b}$ \\
\hline $70-79(n=467)$ & $31.10 \pm 20.42^{c}$ & Stage I HTN (302) & $29.15 \pm 19.48^{b}$ \\
\hline$>79(n=114)$ & $46.00 \pm 23.15^{d}$ & Stage 2 HTN (95) & $36.22 \pm 23.74^{c}$ \\
\hline $\mathrm{p} * *$ & $<0.001$ & $\mathrm{P} * *$ & $<0.001$ \\
\hline
\end{tabular}

* Mean \pm standard deviation

**P-value is for one-way analysis of variance

a,b,c, same letters indicate statistical insignificance based on Duncan's multiple comparisons. Normal: $\mathrm{SBP}<120 \mathrm{~mm} \mathrm{Hg}$ and DBP $<80 \mathrm{~mm} \mathrm{Hg}$, prehypertension: $120 \leq \mathrm{SBP}<140 \mathrm{~mm} \mathrm{Hg}$ or $80 \leq \mathrm{DBP}<90 \mathrm{~mm} \mathrm{Hg}$, stage I: $140 \leq \mathrm{SBP}<160 \mathrm{~mm} \mathrm{Hg}$ or $90 \leq \mathrm{DBP}<100 \mathrm{~mm} \mathrm{Hg}$, stage 2: SBP $\geq 160$ or $\mathrm{DBP} \geq 100 \mathrm{~mm} \mathrm{Hg}$.

hypertensive patients did not take antihypertensives (Table 1) and therefore their blood pressure was not well controlled. Another possible explanation is that even among hypertensive patients complying with treatment, $37.2 \%$ suffered from uncontrolled HTN (Figure 1-A). The 10 -year probability of stroke increased in proportion to blood pressure even among patients being treated for hypertension (Table 2). These findings demonstrate that stricter control of HTN may be an important intervention for prevention of stroke.

In HTN stage 2, the 10-year probability of stroke was higher in women compared to that of men, but in other
HTN stages, there was no difference between men and women (Figure 2-B). Female patients in HTN stage 2, were older than their male counterparts, but this difference was not observed in other HTN stages. In addition, the distributions of other risk factors did not segregate by gender at any other stage of HTN (data not shown). Therefore, we believe that the difference in the 10-year probability of stroke between men and women for HTN stage 2 is related to age.

The 10-year probability of stroke in HTN patients increased in proportion to age (Table 2) but the distribution of 10-year probability of stroke between men and
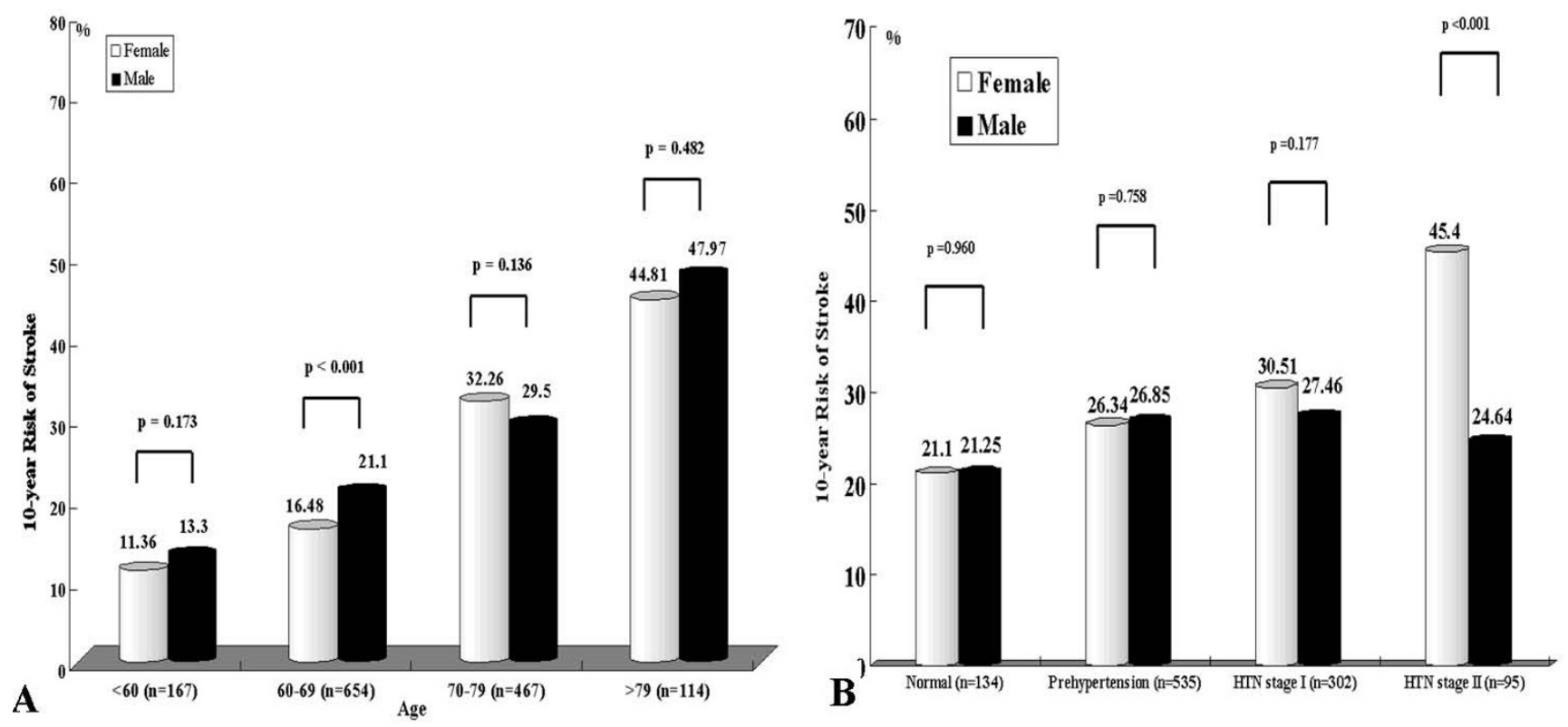

\section{Figure 2}

A: The average 10 -year risk of stroke according to age in men and women with hypertension. $\mathrm{B}$ : The difference in average I0-year probability of stroke between men and women, according to HTN stage. Normal is SBP $<120 \mathrm{mmHg}$ and $\mathrm{DBP}<80 \mathrm{mmHg}$, Pre-hypertension is $120 \leq \mathrm{SBP}<140 \mathrm{mmHg}$ or $80 \leq \mathrm{DBP}<90 \mathrm{mmHg}$, HTN stage I is I40 $\leq$ SBP $<160$ $\mathrm{mmHg}$ or $90 \leq \mathrm{DBP}<100 \mathrm{mmHg}$, HTN stage 2 is $\mathrm{SBP} \geq 160$ or DBP $\geq 100 \mathrm{mmHg}$. 


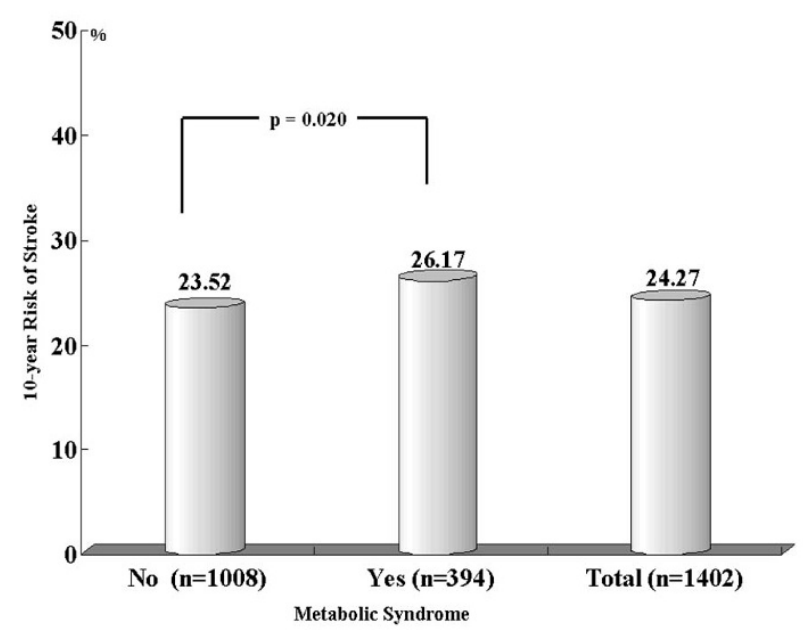

Figure 3

The average I0-year risk of stroke according to metabolic syndrome.

women varied according to age. In the 60-69 year age group, the 10-year probability of stroke was higher for men than for women, but in other age groups there was no difference by gender (Figure 2-A). In the 60-69 year age group, frequencies of history of CVD and LVH were higher for men than for women, but not in other age groups. The distribution of other risk factors between men and women did not differ according to age (data not shown). Therefore, we believe that differences in the 10year probability of stroke between men and women in aged 60-69 are driven by the distribution of CVD and LVH.

The prevalence of diabetes mellitus in hypertensive patients was $16 \%$ (17.2\% women, $14.7 \%$ men; Table 1$)$, which was higher than that seen in the Korean National Health and Nutrition Examination Survey [19]. This study showed that, in the Korean population, the prevalence of diabetes mellitus was $9.1 \%$ (7.9\% women, $10.2 \%$ men).
Our enrolled subjects were older and considered high risk patients, which may explain the discrepancy.

The prevalence of dyslipidemia in our sample of hypertensive patients was $12.6 \%$ (7.9\% women, $16.6 \%$ men; Table 1). This prevalence was lower than that observed by the Korean National Health and Nutrition Examination Survey (2005) [19]. That study showed that, in the general Korean population, the prevalence of dyslipidemia was $48.3 \%$ (38.2\% women, 58.9\% men). Our enrolled subjects were older and considered high risk patients, and had been prescribed anti-lipid lowering agents, which may explain the discrepancy.

The prevalence of metabolic syndrome in our sample of hypertensive patients measured according to the ATP-III guideline was 28\% (26.1\% women, 30.5\% men; Figure 1B). This result was similar to values found by the Korean National Health and Nutrition Examination Survey (2005) [19]. That study showed that, in the general Korean population, the prevalence of metabolic syndrome was 29.5\% (26.1\% women, 33.1\% men). Another report suggests that metabolic syndrome is an important risk factor for ischemic stroke [20]. According to our results, the 10-year risk of stroke is higher for patients suffering from metabolic syndrome (Figure 3).

In Korea, $\mathrm{ARB}$ was the most frequently prescribed antihypertensive at $48.6 \%$, with the next being CCB (38.7\%). Cardiologists working at general hospitals tend to prefer $\mathrm{ARB}$ to other antihypertensives due to higher compliance and fewer side effects., Many clinical papers demonstrating positive effects of ARB for the prevention of stroke and cardiovascular diseases have been published recently [21]. The prescription frequency of ACEI was only 9.9\%, probably due to side effects such as cough, and a general preference for ARB. Diuretics were more frequently prescribed for older patients than for younger patients. This may be due to a high prevalence of complications, such as ischemic heart disease and heart failure, in older patients.

Table 3: Concomitant antihypertensives according to age

\begin{tabular}{ccccccc}
\hline Drug, $\mathbf{n}(\%)$ & $\mathbf{6 0}$ & $\mathbf{6 0 - 6 9}$ & $\mathbf{7 0 - 7 9}$ & $\mathbf{7 9}$ & Total \\
\cline { 2 - 5 } & $(\mathrm{n}=167)$ & $(\mathrm{n}=654)$ & $(\mathrm{n}=467)$ & $(\mathrm{n}=114)$ & $(\mathrm{n}=1402)$ & $\mathrm{P}$ \\
\hline ACEI & $25(15.0)$ & $53(8.1)$ & $48(10.3)$ & $13(11.4)$ & $139(9.9)$ & 0.057 \\
ARB & $76(45.5)$ & $325(49.7)$ & $220(47.1)$ & $60(52.6)$ & $681(48.6)$ & 0.55 \\
BB & $49(29.3)$ & $203(31.0)$ & $156(33.4)$ & $34(29.8)$ & $442(31.5)$ & 0.716 \\
CCB & $66(39.5)$ & $261(39.9)$ & $176(37.7)$ & $39(34.2)$ & $542(38.7)$ & 0.655 \\
Diuretics & $9(5.4)$ & $39(6.0)$ & $52(11.1)$ & $10(8.8)$ & $110(7.8)$ & 0.008 \\
Combined Antihypertensives & $55(32.9)$ & $222(33.9)$ & $183(39.2)$ & $43(37.7)$ & $503(35.9)$ & 0.253 \\
\hline
\end{tabular}

ACEl: angiotensin converting enzyme inhibitor, ARB: angiotensin receptor blocker, BB: beta-blocker, CCB: calcium channel blocker. Combined antihypertensive treatment: take more than two antihypertensive drugs. 
Among Korean hypertensive patients, 35.9\% took more than two antihypertensive drugs (Table 3). This frequency was similar to that in seen in the United States $35.8 \%$, 1999-2002) [22].

In our study, $76 \%$ of hypertensive patients took antihypertensive medication and $63.9 \%$ of patients on antihypertensive medication had controlled HTN (Table 1). These results were high compared to those found by the Korean National Health and Nutrition Examination Survey (2005) [19], but this may be explained by the fact that our study population was derived from a highly selected group of patients who were visiting cardiology clinics for suspected or established cardiac diseases.

This study has some limitations. First, our study population was derived from a highly selected group of patients who were visiting tertiary hospitals for suspected or established cardiac diseases. Although it is appropriate to do a collective study with the cooperation of community based hospitals, public health centers, and general hospitals, our study included only tertiary hospitals. Therefore, cardiovascular risk factors are overrepresented in our sample. Second, this study was a simple cross-sectional study and did not consider information about practical stroke events. Therefore, we could not compare 10 -year probability of stroke with real stroke incidence. Third, we did not directly compare the 10-year probability of stroke for our hypertensive sample and the KCPS cohort [10]. Fourth, we assessed smoking status with a single, selfreported questionnaire. Therefore, non-differential misclassification is possible.

\section{Conclusion}

In conclusion, the average 10-year probability of stroke in our hypertensive sample was $26.27 \%$, and this level was approximately 2.4 times higher than that seen in the KCPS cohort. The probability of stroke in our sample increased with severity of blood pressure in treated hypertensive patients. We suggest that stricter control of HTN may prove to be an important intervention for preventing stroke.

\section{Competing interests}

The authors declare that they have no competing interests.

\section{Authors' contributions}

Cheol Ung Choi participated in the design of the study, analysed and interpreted data and drafted the manuscript. Chang Gyu Park conceived of the study and participated in its design and critically revised the manuscript. All authors read and approved the final manuscript.

\section{Acknowledgements}

This study was supported by MSD Korea and Seoul R\&BD Program (10526).
We are grateful to all staff involved in the collection of data at the different centers and all participants for their cooperation in the study.

\section{References}

I. Korea National Statistical Office: Year Book of Cause of Death. 2004.

2. National Health Insurance Corporation: 2005 National Health Insurance Statistical Yearbook Seoul Korea: Health Insurance Review Agency and National Health Insurance corporation.

3. Andrawes WF, Bussy C, Belmin J: Prevention of cardiovascular events in elderly people. Drugs Aging 2005, 22:859-76.

4. Kim JS, Yoon SS: Perspectives of stroke in persons living in Seoul, South Korea. A survey of 1000 subjects. Stroke 1997, 28: I 165-9.

5. Kannel WB, Wolf PA, Verter J, McNamara PM: Epidemiologic assessment of the role of blood pressure in stroke; the Framingham Study. JAMA 1996, 276:1269-78.

6. Lewington S, Clarke R, Qizilbash N, Peto R, Collins R, Prospective Studies Collaboration: Age specific relevance of usual blood pressure to vascular mortality: A meta-analysis of individual data for one million adults in $6 \mathrm{I}$ prospective studies. Lancet 2002, 360: 1903-13.

7. Wolf PA, D'Agostino RB, Belanger AJ, Kannel WB: Probability of stroke: a risk profile from the Framingham Study. Stroke 1991, 22:312-8.

8. Kannel WB, Wolf PA, McGee DL, Dawber TR, McNamara P, Castelli WP: Systolic blood pressure, arterial rigidity and risk of stroke: The Framingham Study. JAMA 198I, 245: I225-9.

9. Lassen NA: Epidemiologic assessment of the role of blood pressure in stroke. JAMA 1996, 276:1269-78.

10. Jee SH, Park JW, Lee SY, Nam BH, Ryu HG, Kim SY, Kim YN, Lee JK, Choi SM, Yun JE: Stroke risk prediction model: $A$ risk profile from the Korean study. Atherosclerosis 2008, 197:318-25.

II. Park CG, Choi CU: Probability of stroke in Korean hypertensive patients visiting community-based hospitals: using a riskprofile from the Framingham study. J Hum Hypertens 23(4):252-258.

12. Chobanian AV, Bakris GL, Black HR, Cushman WC, Green LA, Izzo JL Jr, Jones DW, Materson BJ, Oparil S, Wright JT Jr, Roccella EJ: The Seventh Report of the Joint National Committee on Prevention, Detection, Evaluation, and Treatment of High Blood Pressure: the JNC 7 report. J Am Med Assoc 2003, 289:2560-2572.

13. Molloy TJ, Okin PM, Devereux RB, Kligfield P: Electrocardiographic detection of left ventricular hypertrophy by the simple QRS voltage-duration product. J Am Coll Cardiol 1992, 20: I 180-6.

14. Okin PM, Roman MJ, Devereux RB, Kligfield P: Electrocardiographic identification of increased left ventricular mass by simple voltage-duration products. J Am Coll Cardiol 1995, 25:4I7-23.

15. Sokolow M, Lyon TP: The ventricular complex in left ventricular hypertrophy as obtained by unipolar precordial and limb leads. Am Heart J 1949, 37: 16 I-86.

16. Expert Panel on Detection, Evaluation, and Treatment of High Blood Cholesterol in Adults: Executive Summary of the Third Report of the National Cholesterol Education Program (NCEP) Expert Panel on Detection, Evaluation, and Treatment of High Blood Cholesterol in Adults (Adult Treatment Panel III). JAMA 200I, 285:2486-2497.

17. European Society of Hypertension-European Society of Cardiology guidelines for the management of arterial hypertension Guidelines Committee. J Hypertens 2003, 2 I : I0 I I-53.

18. Dodson PM, Lip GYH, Eames SM, Gibson JM, Beevers DG: Hypertensive retinopathy: A review of existing classification systems and a suggestion for a simplified grading system. J Hum Hypertens 1996, I0:93-98.

19. Korean National Health and Nutrition Examination Survey. 2005.

20. Boden-Albala B, Sacco RL, Lee HS, Grahame-Clarke C, Rundek T, Elkind MV, Wright C, Giardina EG, DiTullio MR, Homma S, Paik MC: Metabolic syndrome and ischemic stroke risk: Northern Manhattan Study. Stroke 2008, 39:30-5. 
21. Lindholm LH, Ibsen H, Dahlöf B, Devereux RB, Beevers G, de Faire $U$, Fyhrquist F, Julius S, Kjeldsen SE, Kristiansson K, Lederballe-Pedersen O, Nieminen MS, Omvik P, Oparil S, Wedel H, Aurup P, Edelman J, Snapinn S, LIFE Study Group: Cardiovascular morbidity and mortality in the Losartan Intervention For Endpoint reduction in hypertension study (LIFE): a randomised trial against atenolol. Lancet 2002, 359:995-1003.

22. Gu Q, Paulose-Ram R, Dillon C, Burt V: Antihypertensive medication use among US adults with hypertension. Circulation 2006, I| 3:2|3-2|.

\section{Pre-publication history}

The pre-publication history for this paper can be accessed here:

http://www.biomedcentral.com/1471-2377/9/16/prepub

Publish with Bio Med Central and every scientist can read your work free of charge

"BioMed Central will be the most significant development for disseminating the results of biomedical research in our lifetime. "

Sir Paul Nurse, Cancer Research UK

Your research papers will be:

- available free of charge to the entire biomedical community

- peer reviewed and published immediately upon acceptance

- cited in PubMed and archived on PubMed Central

- yours - you keep the copyright

Submit your manuscript here:

http://www.biomedcentral.com/info/publishing_adv.asp 